\title{
Testing steady-state analysis of single-ring and square pressure infiltrometer data
}

\author{
V. Bagarello ${ }^{\text {a }}$ M. Iovino ${ }^{\text {a }}$ J. Lai ${ }^{\text {b,* }}$ \\ a Dipartimento di Scienze Agrarie e Forestali, Università degli Studi di Palermo, Viale delle Scienze, Palermo 90128, Italy \\ ${ }^{\mathrm{b}}$ Key Laboratory of Ecosystem Network Observation and Modeling, Institute of Geographic Sciences and Natural Resources Research, Chinese Academy of Sciences, Beijing 100101, China
}

\section{A R T I C L E I N F O}

\section{Article history:}

Received 16 November 2014

Received in revised form 25 June 2015

Accepted 5 July 2015

Available online 30 July 2015

\section{Keywords:}

Saturated soil hydraulic conductivity

Single-ring pressure infiltrometer

Square infiltrometer

Numerical simulation

\begin{abstract}
A B S T R A C T
Testing reliability of the saturated soil hydraulic conductivity, $K_{s}$, estimated by applying the steady-state singlering (SR) model to the quasi steady-state infiltration rates obtained with a single-ring pressure infiltrometer (PI) increases confidence in the estimated $K_{s}$ values. Determining a means to estimate $K_{s}$ from infiltration data collected with a square infiltrometer allows the use of sources of different shapes. Using numerically simulated infiltration rates for six homogeneous soils ranging in texture from sand to silty clay loam, this investigation suggested an overall good performance of the SR model, with estimated $K_{s}$ values differing by not more than $25 \%$ from the true values for the $90 \%$ of the 96 considered runs. Larger errors were generally obtained for the silty clay loam soil. Even in this case, however, a small ring radius $(0.038 \mathrm{~m})$, a relatively high initial soil water content (initial effective saturation $=0.4)$ and a relatively high depth of ponding $(0.10 \mathrm{~m})$ allowed the obtainment of accurate predictions of $K_{s}$ (error $=13 \%$ ) with a run of practically sustainable duration ( $4 \mathrm{~h}$ ). The SR model was also usable to analyze quasi steady-state infiltration data collected with a square infiltrometer when infiltration was assumed to occur through a circular source having the same area of the square infiltrometer. With this assumption, the estimates of $K_{S}$ differed from the true values by not more than a practically negligible $16 \%$. The results of this investigation should help better interpret $K_{s}$ values obtained with the PI and also improve the experimental methodology, depending on the soil. Moreover, a wider applicability of the infiltrometer techniques, i.e. not limited to a circular source, can be expected. Soil heterogeneity should be taken into account in the future since heterogeneity is common in the field.
\end{abstract}

(C) 2015 Elsevier B.V. All rights reserved.

\section{Introduction}

The saturated soil hydraulic conductivity, $K_{s}$, is one of the most important soil properties controlling soil hydrologic and erosion processes such as rainfall partition into infiltration and surface runoff. Especially for structured soils, this property should be measured directly in the field to minimize disturbance of the sampled soil volume and to maintain its functional connection with the surrounding soil (Bouma, 1982). Reliable field data should be collected with a reasonably simple and rapid experiment.

The single-ring pressure infiltrometer (PI) (Reynolds and Elrick, 1990) is a practically simple device that has frequently been applied in the field in the past 20 years (Vauclin et al., 1994; Ciollaro and Lamaddalena, 1998; Bagarello and Iovino, 1999; Angulo-Jaramillo et al., 2000; Bagarello et al., 2000, 2013a, 2014; Reynolds et al., 2000; Bagarello and Sgroi, 2004; Mertens et al., 2002; Gómez et al., 2005; Verbist et al., 2009, 2010, 2013). This technique uses a small radius metal ring that is inserted into the soil to a short depth. A constant hydraulic head, $H$, is established within the infiltration ring and flow rate into the soil is monitored. Flow

\footnotetext{
* Corresponding author.

E-mail address: laijianbin@igsnrr.ac.cn (J. Lai).
}

goes through an initial decreasing phase and then it approaches steadystate conditions (Elrick and Reynolds, 1992b). Three-dimensional, steady, ponded flow out of the ring is then used to determine $K_{s}$ with an analysis, developed by Reynolds and Elrick (1990), based on variably saturated flow theory and including the hydrostatic pressure, capillarity and gravity components of flow out of the ring. This analysis employs shape factors that were numerically determined for three soils (sand, loam and clay) and a clay cap/liner. To our knowledge, the steady analysis by Reynolds and Elrick (1990) has not been assessed against simulated PI experiments performed in different soils and involving a transient infiltration phase, as it occurs in real field conditions.

The analysis by Reynolds and Elrick (1990), as well as other PI analyses (Wu et al., 1999), applies to a circular source but using sources of different shapes could be advisable in particular circumstances. For example, a square infiltrometer could allow, at least in theory, to sample completely an area of interest whereas, with a circular source, there are zones of the field that cannot be sampled, thus precluding the possibility to uniformly collect data. This is a possible limitation of this device since intensively sampling soil represents an important step toward an improved interpretation and simulation of hydrological processes at the field scale (Gómez et al., 2005; Bagarello et al., 2013b). Employing a square infiltrometer raises a problem in the calculation of 
$K_{s}$ since the developed equations include the ring radius that has to be replaced by a suitable alternative quantity if a square source is being used. Gómez et al. (2005) used a square infiltrometer and they determined $K_{s}$ by assuming that the ring radius coincided with the side length of the infiltrometer. However, these authors did not test their assumption.

Numerical simulation of an infiltration process into an initially unsaturated porous medium is a powerful tool to test hypotheses and to check factors affecting the applicability of a particular analytical procedure to estimate soil characteristics (Bagarello et al., 2013a). For example, numerically simulated data were used by Wu et al. (1993) to explain erratic $K_{s}$ estimates obtained by the borehole permeameter technique in soils with macropores and abrupt layers. Lai and Ren (2007) and Lai et al. (2010) used numerical simulation to improve determination of $K_{s}$ by the double-ring infiltrometer. Dušek et al. (2009) analyzed single-ring numerically generated data to test the dependence of the infiltration rate on several factors, including ring diameter and insertion depth and ponding depth of water on the infiltration surface. Bagarello et al. (2013a) used numerical simulation to test the performances of the two-ponding-depth (TPD) procedure of analysis (Reynolds and Elrick, 1990) for PI data collected in heterogeneous soils. Numerically simulated data were used by Reynolds (2013) to assess different borehole infiltration analyses for determining $K_{s}$ in the vadose zone. Therefore, numerical simulation of a single-ring infiltration process appears suitable to test the steady-state analysis developed for the PI.

In this investigation, numerically simulated infiltration data were used with the following objectives: i) to assess the steady-state analysis developed by Reynolds and Elrick (1990) for a single-ring pressure infiltrometer experiment simulated for different soils, and ii) to determine a means to estimate saturated soil hydraulic conductivity from quasi steady-state infiltration data collected with a square infiltrometer.

\section{Theory}

The analytical expression for steady, ponded flow out of a ring into rigid, homogeneous, isotropic, uniformly unsaturated soil is (Reynolds and Elrick, 1990):

$Q_{s}=\frac{r}{G}\left(K_{s} H+\phi_{m}\right)+\pi r^{2} K_{s}$

where $Q_{S}\left(\mathrm{~L}^{3} \mathrm{~T}^{-1}\right)$ is the steady-state flow rate, $r(\mathrm{~L})$ is the ring radius, $K_{S}$ $\left(\mathrm{L} \mathrm{T}^{-1}\right)$ is the saturated soil hydraulic conductivity, $H(\mathrm{~L})$ is the ponded head of water on the infiltration surface, $\phi_{m}\left(\mathrm{~L}^{2} \mathrm{~T}^{-1}\right)$ is the matric flux potential and $G$ is a dimensionless shape factor expressing the interactions between ring radius, depth of ring insertion, $d(\mathrm{~L})$, depth of ponding in the ring, soil capillarity and gravity. According to Eq. (1), steady-state flow rate out of the ring is the sum of three components, i.e. flow due to the hydrostatic pressure of the established ponding depth of water on the infiltration surface (first term on the right of the equation), flow due to the capillarity of the unsaturated soil under and adjacent to the ring (second term), and flow due to gravity (third term). With a larger source, the relative contribution of both the hydrostatic pressure and the soil capillarity to total flow decreases whereas that of gravity increases (Reynolds et al., 2002). Eq. (1) was developed under the assumption that ponding does not occur around the outside of the ring during a measurement (Reynolds, 2008; Reynolds and Elrick, 2002). Values of $G$ for a circular source, four porous media and different combinations of $H, d$ and $r$ were determined numerically by Reynolds and Elrick (1990). These authors also found that $G$ is nearly independent of soil hydraulic properties and $H$ for $H \geq 0.05 \mathrm{~m}$. Therefore, for practical application of the PI technique, the following relationship, specifically developed for $0.03 \mathrm{~m} \leq d \leq 0.05 \mathrm{~m}, 0.05 \mathrm{~m} \leq r \leq 0.10 \mathrm{~m}$ and
$0.05 \mathrm{~m} \leq H \leq 0.25 \mathrm{~m}$, can be used to obtain an estimate of $G\left(G_{e}\right)$ (Reynolds and Elrick, 1990):

$G_{e}=0.316 \frac{d}{r}+0.184$

For a given insertion depth, $G_{e}$ is a function of the ring radius. According to Reynolds and Elrick (2002), however, Eq. (2) is usable for practical purposes within wider ranges of both $d(0<d \leq 0.10 \mathrm{~m})$ and $H(0.05 \leq H \leq 1 \mathrm{~m})$ without substantially compromising the reliability of the estimates (Youngs et al., 1993).

Eq. (1), with Eq. (2) inserted, can be written as (Reynolds and Elrick, 1990):

$K_{s}=\frac{\alpha^{*} G_{e} Q_{s}}{r\left(\alpha^{*} H+1\right)+G_{e} \alpha^{*} \pi r^{2}}$

where $\alpha^{*}\left(\mathrm{~L}^{-1}\right)$ is equal to:

$\alpha^{*}=\frac{K_{s}}{\phi_{m}}$

The $\alpha^{*}$ parameter is expressive of the relative importance of gravity and capillarity flow. A large $\alpha^{*}$ suggests low capillarity due to coarse soil texture or extensive soil structure and vice versa. In this investigation, Eq. (3) was indicated as the SR (i.e., single-ring) model for $K_{s}$ calculation.

The ring infiltrometer equation for steady ponded flow can be recast as:

$i_{s}=\frac{Q_{s}}{\pi r^{2}}=\frac{Q_{s}}{A}=\left[\frac{r}{A G_{e}{ }^{e}}\left(H+\alpha^{*-1}\right)+1\right] K_{s}$

where $i_{s}\left(\mathrm{LT}^{-1}\right)$ is the steady infiltration rate and $A\left(\mathrm{~L}^{2}\right)$ is the area of the infiltration surface. According to Eq. (5), $K_{S}$ depends on steady infiltration and, as a consequence, all shapes (e.g. circles, squares, rectangles, triangles) could be expected to yield the same $i_{s}$ and $K_{s}$ values if they have the same total infiltration surface. However, a necessary passage to apply Eq. (3) with a non-circular source is to assume that the source is circular, so that an equivalent radius can be defined. This assumption needs testing because Eq. (3) was explicitly developed with reference to a circular source but, for a given equivalent radius, the wetted perimeter per unit surface area changes with the shape of the source. Only to make an example, Eq. (3) with $r=10 \mathrm{~cm}$ could indifferently be used with a circular source of $r=10 \mathrm{~cm}$, a square source with a side length of $17.72 \mathrm{~cm}$, and a rectangular source of $2.5 \times 125.7 \mathrm{~cm}^{2}$. All these sources have the same infiltration area $\left(A=314 \mathrm{~cm}^{2}\right)$ but they differ by the wetted perimeter (circular, $63 \mathrm{~cm}$; square, $71 \mathrm{~cm}$; rectangular, $256 \mathrm{~cm}$ ).

\section{Materials and methods}

\subsection{Soils and numerical simulations}

Numerical simulations were carried out for the six homogeneous soils selected by Hinnell et al. (2009). Soil hydraulic properties were modeled according to the van Genuchten-Mualem model (Mualem, 1976; van Genuchten, 1980) with hydraulic parameters taken from Carsel and Parrish (1988) (Table 1):

$$
\begin{aligned}
& \Theta(h)=\frac{\theta(h)-\theta_{r}}{\theta_{s}-\theta_{r}}=\left(1+\left|\alpha_{v G} h\right|^{n}\right)^{-m} \quad m=1-\frac{1}{n} \\
& K(h)=K_{s} \Theta^{0.5}\left(1-\left(1-\Theta^{1 / m}\right)^{m}\right)^{2}
\end{aligned}
$$

where $\Theta$ is the effective saturation, $h(\mathrm{~L})$ is the soil water pressure head, $\theta\left(\mathrm{L}^{3} \mathrm{~L}^{-3}\right)$ is the volumetric soil water content, $\theta_{S}\left(\mathrm{~L}^{3} \mathrm{~L}^{-3}\right)$ and $\theta_{r}\left(\mathrm{~L}^{3} \mathrm{~L}^{-3}\right)$ are the saturated and residual volumetric water contents, respectively, $\alpha_{v G}\left(L^{-1}\right), m$ and $n$ are soil-specific empirical parameters of the van 
Table 1

Mualem-van Genuchten soil hydraulic model parameters (Carsel and Parrish, 1988; Hinnell et al., 2009), and values of the initial soil water pressure head, $h_{i}$, and the $\alpha^{*}$ parameter.

\begin{tabular}{|c|c|c|c|c|c|c|c|c|c|c|}
\hline \multirow[t]{2}{*}{ Soil } & \multirow[t]{2}{*}{$\theta_{\mathrm{r}}$} & \multirow[t]{2}{*}{$\theta_{\mathrm{s}}$} & \multirow[t]{2}{*}{$a_{v G}\left(\mathrm{~cm}^{-1}\right)$} & \multirow[t]{2}{*}{$\mathrm{n}$} & \multirow[t]{2}{*}{$\mathrm{m}$} & \multirow[t]{2}{*}{$K_{s}\left(\mathrm{~cm} \mathrm{~h}^{-1}\right)$} & \multicolumn{2}{|l|}{$\Theta_{i}=0.05$} & \multicolumn{2}{|c|}{$\Theta_{i}=0.4$} \\
\hline & & & & & & & $h_{i}(\mathrm{~m})$ & $\alpha^{*}\left(\mathrm{~m}^{-1}\right)$ & $h_{i}(\mathrm{~m})$ & $\alpha^{*}\left(\mathrm{~m}^{-1}\right)$ \\
\hline Sand, S & 0.045 & 0.43 & 0.145 & 2.68 & 0.627 & 29.7 & 0.41 & 26.26 & 0.11 & 26.50 \\
\hline Loamy sand, LS & 0.057 & 0.41 & 0.124 & 2.28 & 0.561 & 14.6 & 0.84 & 26.04 & 0.15 & 26.27 \\
\hline Sandy loam, SAL & 0.065 & 0.41 & 0.075 & 1.89 & 0.471 & 4.42 & 3.86 & 20.13 & 0.34 & 20.28 \\
\hline Loam, L & 0.078 & 0.43 & 0.036 & 1.56 & 0.359 & 1.04 & 58.5 & 14.45 & 1.35 & 14.51 \\
\hline Silt loam, SIL & 0.067 & 0.45 & 0.020 & 1.41 & 0.291 & 0.45 & 745.1 & 11.17 & 4.53 & 11.20 \\
\hline Silty clay loam, SCL & 0.089 & 0.43 & 0.010 & 1.23 & 0.187 & 0.07 & 453,597 & 11.65 & 53.4 & 11.65 \\
\hline
\end{tabular}

Genuchten-Mualem model, and $K\left(\mathrm{~L} \mathrm{~T}^{-1}\right)$ is the unsaturated soil hydraulic conductivity. These soils were chosen since they were appropriate for studying three-dimensional infiltration processes into an initially unsaturated porous medium from a small-size source according to Hinnell et al. (2009). Moreover, the selected soils differed widely by their hydraulic properties, allowing the exploration of a wide range of situations, including those where equilibration times of the PI runs are expected to be rather long (Reynolds, 2008).

A three dimensional flow domain (Fig. 1) was adopted for all simulations by using the HYDRUS-2D/3D software package (Šimůnek et al., 2007), which is widely employed for simulating water, heat, and/or solute movement in two or three dimensions (Shan and Wang, 2012; Reynolds and Lewis, 2012). The side length of the square flow domain in the $\mathrm{X}-\mathrm{Y}$ plane was $140 \mathrm{~cm}$ and the depth in the $\mathrm{Z}$ direction was $180 \mathrm{~cm}$. The outer border was at least $55 \mathrm{~cm}$ away from the infiltrometer (ponding area) even for the largest infiltrometer (side length, $l$, or ring diameter, $2 r=30 \mathrm{~cm}$ ). The bottom of the flow domain was also far below the possible wetting zone (Fig. 2). Therefore, both the lateral and the bottom boundaries had a negligible effect on the infiltration process. To improve the computation efficiency as well as the simulation accuracy, a variable mesh size of finite-element mesh was generated using the MESHGEN subroutine embedded in the HYDRUS2D/3D software package. In the $\mathrm{X}-\mathrm{Y}$ plane (Fig. 1 ), mesh size was refined within and around the infiltrometer and a minimum mesh size of $1 \mathrm{~cm}$ was adopted. Then the mesh size gradually increased to a maximum of $5 \mathrm{~cm}$ for the other part of the flow domain. In the $Z$ direction, the sub-layer thickness was $1 \mathrm{~cm}(d Z=1 \mathrm{~cm})$ for the top $20 \mathrm{~cm}$ and $2 \mathrm{~cm}$ for the subsequent $20 \mathrm{~cm}$ in depth. Then the thickness of sub-layers gradually increased to a maximum of approximately $10 \mathrm{~cm}$ until the total depth of the flow domain reached $180 \mathrm{~cm}$. For the silty clay loam (SCL) soil, this spatial discretization yielded mass balance errors higher than $1 \%$, that were considered unacceptable for numerical simulations (Celia et al., 1990; Rathfelder and Abriola, 1994; Jacques et al., 2006). Haverkamp et al. (1977) compared different numerical schemes and considered as "good" or "excellent" mass balance errors in the range from 0.2 to $0.4 \%$. To reduce the mass balance errors in the SCL soil, a finer spatial discretization was used which consisted of a $0.5 \mathrm{~cm}$ mesh size within and around the infiltrometer (in the X-Y plane) and $0.5 \mathrm{~cm}$ in the thickness of sub-layer (depth in $\mathrm{Z}$ direction). For the other soils, an explorative test conducted with this finer spatial discretization did not yield practical differences in simulated cumulative infiltration curves. A similar result was found by Lai et al. (2010) who concluded that the nodal spacing had a negligible impact on the simulation results. Therefore, the results obtained with the coarser mesh discretization were used for the other soils.

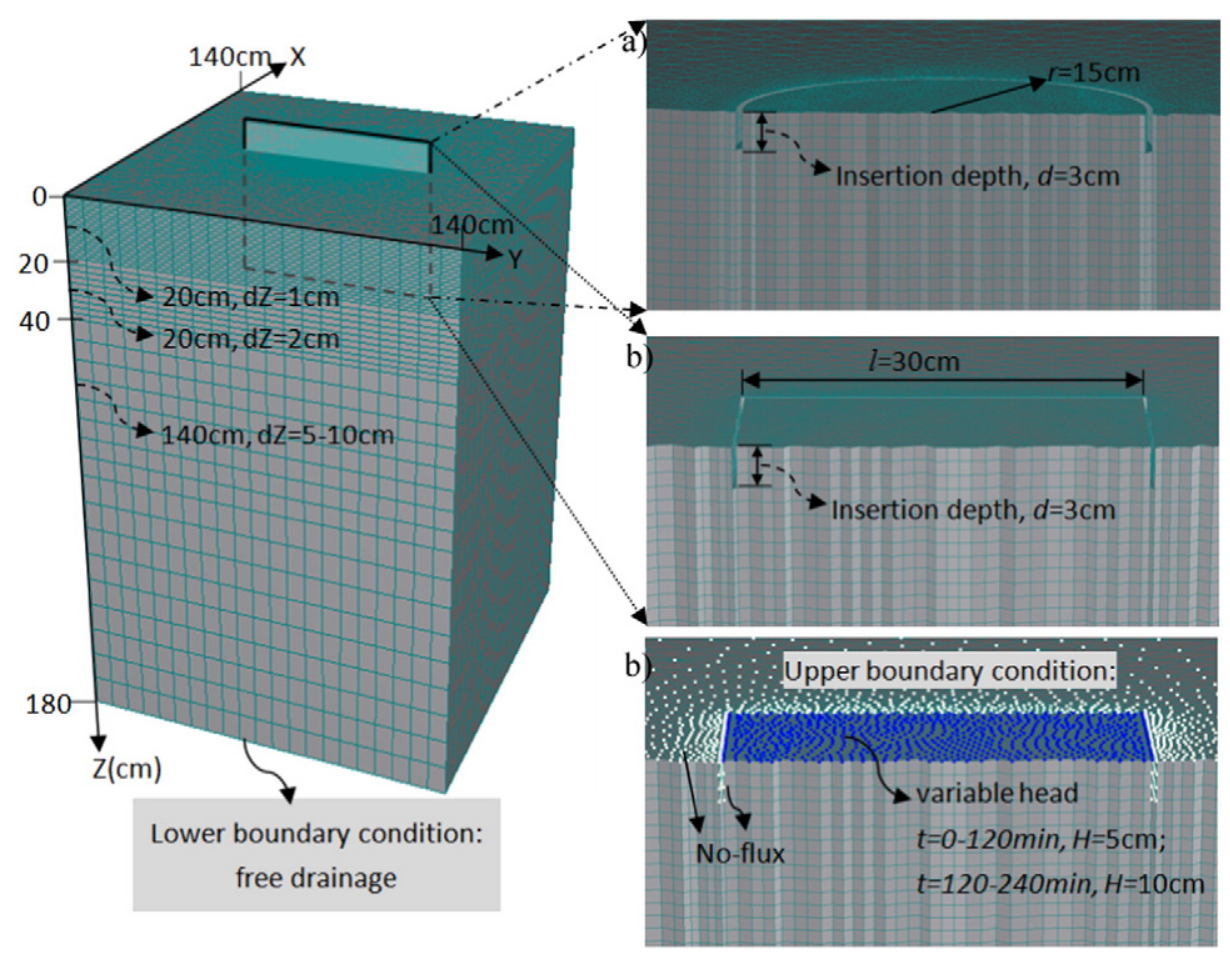

Fig. 1. Geometry and boundary conditions of the simulation domain for a) ring infiltrometer with radius $r=15 \mathrm{~cm}$, and b) square infiltrometer with side length $l=30 \mathrm{~cm}$. 

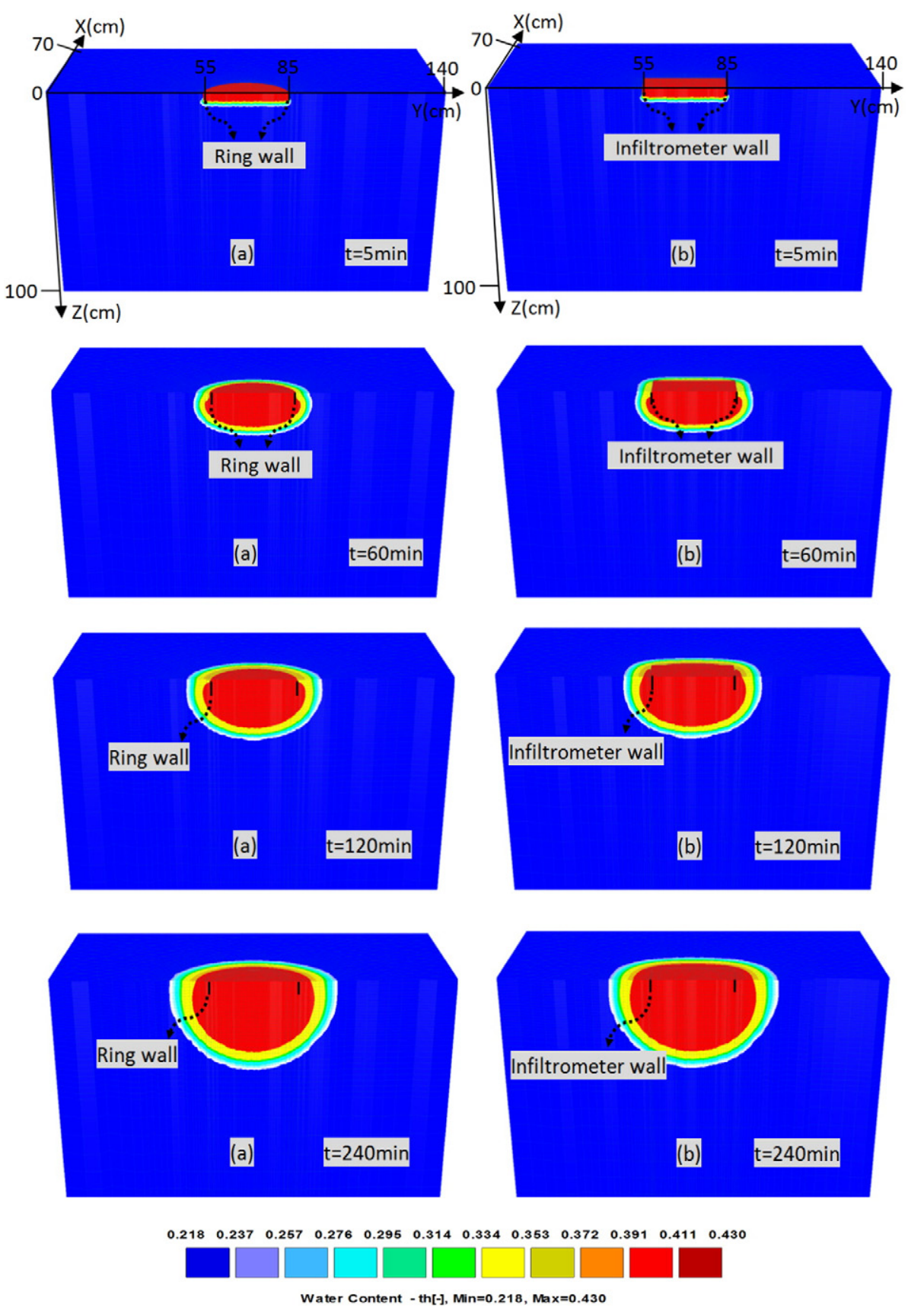

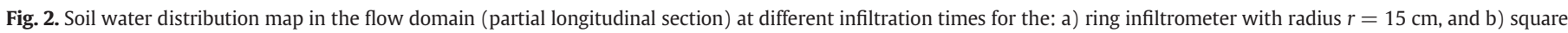
infiltrometer with side length $l=30 \mathrm{~cm}$ (loam soil, high initial water content).

A variable time step was adopted to reduce the computation time while assuring simulation accuracy. The initial, minimum, and maximum time steps were 10,1 , and $60 \mathrm{~s}$, respectively. For the SCL soil, these values were equal to 5,1 , and 60 s, respectively, to improve simulation accuracy.

A circle notch or a square notch was generated and centered on the flow domain to represent the infiltrometer wall (Fig. 1). The crosssection of the notch was $0.5 \mathrm{~cm}$ in width and $3 \mathrm{~cm}$ (or $5 \mathrm{~cm}$ ) in depth, which is equal to the insertion depth of the infiltrometer. The boundary condition on and outside the notch was no-flux, while two successive constant heads were adopted within the infiltrometer to represent a ponding head condition. The first ponding head, $H_{1}=0.05 \mathrm{~m}$, was maintained for the first $120 \mathrm{~min}$ of simulation whereas the second ponding head, $\mathrm{H}_{2}=0.10 \mathrm{~m}$, was maintained for the following $120 \mathrm{~min}$. The bottom condition of the flow domain was free drainage.
The absolute water content tolerance was 0.0005 (0.05\%), the absolute pressure head tolerance was $0.5 \mathrm{~cm}$, and the maximum number of iterations allowed during any time step was 10 . However, for the simulations with the SCL soil, the water content and pressure head tolerances were set at $0.001(0.1 \%)$ and $1 \mathrm{~cm}$, respectively, because the HYDRUS software package couldn't run properly with higher convergence criteria in those cases.

Simulations were carried out for both an initially dry condition, i.e. $\Theta_{i}=0.05$, and an initially wet condition, i.e. $\Theta_{i}=0.4$, since these values of $\Theta_{i}$ defined the range of initial soil wetness conditions considered by Hinnell et al. (2009). Another reason was that the lower $\Theta_{i}$ value was considered appropriate since the method applies to unsaturated conditions and $\Theta_{i}=0.05$ was representative of a very dry initial condition. The upper $\Theta_{i}$ value was thought to be practically plausible since inserting the ring in relatively wet soil is reasonably easy and the risk 
to destroy soil structure should be reduced in these soil water conditions (Reynolds, 2008). Therefore, applying the PI on an initially relatively wet soil could have practical interest. However, a test of the choice of a relatively high initial soil water content, determining high soil water pressure heads at the beginning of the run for some soils (Table 1), was carried out since the analysis by Reynolds and Elrick (1990) was developed for conditions giving near-maximum soil capillarity. In other terms, it was thought that, for a given soil, $\Theta_{i}=0.4$ was a plausible initial condition if the $\alpha^{*}$ values corresponding to $\Theta_{i}=$ 0.05 and $\Theta_{i}=0.4$ were similar (near-maximum capillarity even in relatively wet initial conditions). A theoretical value of $\alpha^{*}$ was obtained, for given soil and $\Theta_{i}$, by using Eq. (4) with the soil-specific $K_{s}$ value (Table 1 ) and integrating Eq. (6b) to calculate $\phi_{m}$. Note also that when the $K(h)$ function has $K_{s}$ as a multiplier, as in Eq. (6b), $\alpha^{*}$ is independent of the $K_{s}$ value (Reynolds, 2011). For an initial pressure head, $h_{i}$, the pressure head range from $h=h_{i}$ to $h=0$ was subdivided by considering the following steps: $0.001 \mathrm{~m}$ for $0 \leq|h| \leq 150 \mathrm{~m} ; 0.01 \mathrm{~m}$ for $150<|h| \leq 1500 \mathrm{~m}$; $0.1 \mathrm{~m}$ for $1500<|h| \leq 15,000 \mathrm{~m} ; 1 \mathrm{~m}$ for $|h|>15,000 \mathrm{~m}$. For each $\Delta|h|$ value, the area under the hydraulic conductivity curve was calculated by the trapezium rule. The calculations of $\alpha^{*}$ (Table 1 ) showed a small and practically negligible sensitivity of this parameter to the initial saturation degree since it increased by no more than $0.9 \%$ with the increase of $\Theta_{i}$. Therefore, the $\alpha^{*}$ calculations of Table 1 supported the choice to consider $\Theta_{i}=0.05$ and $\Theta_{i}=0.4$ for the numerical simulations. It should be noted that the $\alpha^{*}$ values obtained in this investigation for $\Theta_{i}=0.05$ corresponded perfectly with the range of $\alpha^{*}$ values reported by Reynolds (2010) for the same soils (p. 646, $11.17 \leq \alpha^{*} \leq 26.26 \mathrm{~m}^{-1}$ ) and also with the $\alpha^{*}$ value for the loam soil (p. $643,14.45 \mathrm{~m}^{-1}$ ). Changing $\Theta_{i}$ did not affect, in practice, soil capillarity since $\alpha^{*}$ was nearly constant but it had a detectable effect on the initial pressure head (Table 1). Time to steady-state is known to be longer in dry soil conditions (Reynolds, 2008). Therefore, the possible effect of the initial soil water conditions on the steady-state flow rate estimated with a constant duration infiltration run was taken into account in this investigation.

The range of $\alpha^{*}$ values considered in this study $\left(11.65 \mathrm{~m}^{-1} \leq\right.$ $\alpha^{*} \leq 26.50 \mathrm{~m}^{-1}$ ) fell entirely within the range used in the original development of the ring infiltrometer analysis $\left(1 \mathrm{~m}^{-1} \leq \alpha^{*} \leq 36 \mathrm{~m}^{-1}\right)$ (Reynolds and Elrick, 1990). The difference between the two highest $\alpha^{*}$ values was due to the fact that the sandy soil by Reynolds and Elrick (1990) $\left(K_{s}=360 \mathrm{~mm} \mathrm{~h}^{-1}, \alpha^{*}=36 \mathrm{~m}^{-1}\right)$ did not coincide perfectly with the sandy soil by Carsel and Parrish (1988) $\left(K_{s}=\right.$ $297 \mathrm{~mm} \mathrm{~h}^{-1}, \alpha^{*}=26.50 \mathrm{~m}^{-1}$ ). Values of $\alpha^{*}$ close to $12 \mathrm{~m}^{-1}$ are typical of most field soils (Elrick and Reynolds, 1992a) and lower $\alpha^{*}$ values (e.g., 1-4 $\mathrm{m}^{-1}$ ) correspond to soils with particularly long equilibration times (i.e., many hours or even days; Elrick et al., 1990). This last condition was not considered in this investigation because $K_{s}$ measurement techniques needing attainment of steady-state conditions have a limited practical interest when the expected duration of the infiltration run is very long.

The numerical simulation of a PI run was carried out according to Bagarello et al. (2013a). In particular, a run of the TPD type was simulated since this is a common procedure to apply the PI in the field and Eq. (3) is usable to obtain $K_{s}$ for each $H$ level when two or more depths of ponding are sequentially applied on the infiltration surface (Reynolds and Elrick, 2002). Another reason was that the duration of the transient phase is expected to increase with the depth of water ponding (Reynolds, 2008). Therefore, the TPD run was expected to be a means to reduce in practice ponding depth effects on equilibration times. The initial condition of flow domains was in the form of a uniformly distributed pressure head. For each individual run, $Q_{s 1}$ and $Q_{s 2}$, i.e. the steady-state flow rates corresponding to $H_{1}$ and $H_{2}$, respectively, were estimated by considering the last $10 \mathrm{~min}$ of the process with a given $H$. In particular, $Q_{s 1}$ was calculated by linear regression analysis of the simulated flow rates vs. time for the time interval from $111 \mathrm{~min}$ to $120 \mathrm{~min}$. For $Q_{s 2}$, flow rates from $231 \mathrm{~min}$ to $240 \mathrm{~min}$ were considered.
A circular source and three equivalent square sources were considered for the simulations. In particular, for a given ring radius, equivalence with the square infiltrometer was established in terms of i) wetted perimeter (WP scenario); ii) infiltration surface area (IS scenario); and iii) wetted perimeter per unit infiltration surface area (WPIS scenario). The IS scenario was considered since Eq. (5) suggested that a given total area should yield the same $i_{s}$ and $K_{s}$ values regardless of the shape of the source. The WP and WPIS scenarios were considered because, for a given area of the infiltration surface, the wetted perimeter may change also appreciably with the shape of the source. Therefore, what happens with a constant perimeter (both in absolute and in relative, i.e. referred to the infiltration surface, terms) of the ponded area was also tested. Three ring radii, i.e. $0.038,0.075$ and $0.15 \mathrm{~m}$, and a depth of ring insertion of $0.03 \mathrm{~m}$ were considered (Table 2). For the smallest ring, a ring insertion depth of $0.05 \mathrm{~m}$ was also considered. Therefore, four different datasets (Table 2 ) and a total of 384 estimates of $Q_{s}$ were used in this investigation ( 6 soils $\times 2$ values of the initial soil water content $\times 4$ ring radius/insertion depth combinations $\times 4$ infiltration sources $\times 2$ depths of ponding).

\subsection{Data analysis}

An assessment of the SR model was carried out by calculating $K_{s}$ with Eqs. (2) and (3) and the "true" $\alpha^{*}$ value (Table 1 ) for each soil $/ \Theta_{i} / r / d / H$ combination, following an approach recently applied by Reynolds (2013) for the borehole permeameter. This estimate of $K_{s}$, denoted by the symbol $K_{S R E}$, was then compared with the theoretical $K_{s}$ value. The estimates were deemed accurate only when they fell within the range:

$0.75 \leq K_{S R E} / K_{S} \leq 1.25$

Such a stringent accuracy criterion (i.e., $\leq 25 \%$ error) was used because the input data were free of the perturbations embedded in field and laboratory measurements (Reynolds, 2013). However, in the evaluation of the results it was also considered that the same author suggested in the past that an error in $K_{s}$ that does not exceed a factor of three can denote a sufficient level of accuracy for many practical applications (Elrick and Reynolds, 1992a; Reynolds and Elrick, 2002).

Running a transient flow numerical model for a given time and assuming achievement of steady-state conditions at the end of the run was not a means to test the steady flow ring infiltrometer analysis by Reynolds and Elrick (1990) since this analysis was developed using a steady flow numerical model and only the shape factor was evaluated by numerically simulating transient and steady-state saturated-unsaturated flow from a ponded ring. However, a threedimensional infiltration process into an initially unsaturated porous medium is established in the field with the PI, which implies that a transient phase with decreasing infiltration rates and some inaccuracy in the measurement of $Q_{s}$ are typical of any field run. Actually, the infiltration rate is initially large and it decreases with time to approach near steady-state conditions (Elrick and Reynolds, 1992b). Three-dimensional ponded infiltration may achieve true steadystate more slowly than one-dimensional ponded infiltration (Elrick et al., 1990) and a reasonable estimate of steady flow, or quasi steady

Table 2

Geometrical characteristics of the circular and square infiltration sources considered in the investigation.

\begin{tabular}{|c|c|c|c|c|c|}
\hline \multirow{2}{*}{$\begin{array}{l}\text { Dataset } \\
\text { no. }\end{array}$} & \multirow{2}{*}{$\begin{array}{l}\text { Ring } \\
\text { radius } \\
(\mathrm{cm})\end{array}$} & \multirow{2}{*}{$\begin{array}{l}\text { Ring } \\
\text { insertion } \\
\text { depth } \\
(\mathrm{cm})\end{array}$} & \multicolumn{3}{|c|}{ Side length $(\mathrm{cm})$} \\
\hline & & & $\begin{array}{l}\text { Equivalence } \\
\text { by wetted } \\
\text { perimeter }\end{array}$ & $\begin{array}{l}\text { Equivalence } \\
\text { by surface } \\
\text { area }\end{array}$ & $\begin{array}{l}\text { Equivalence by wetted } \\
\text { perimeter per unit } \\
\text { surface area }\end{array}$ \\
\hline 1 & 3.8 & 3.0 & 5.97 & 6.74 & 7.6 \\
\hline 2 & 3.8 & 5.0 & 5.97 & 6.74 & 7.6 \\
\hline 3 & 7.5 & 3.0 & 11.78 & 13.29 & 15.0 \\
\hline 4 & 15.0 & 3.0 & 23.56 & 26.59 & 30.0 \\
\hline
\end{tabular}


flow, is considered acceptable in natural environments (Reynolds and Elrick, 2002). With respect to these points, the testing approach used in this investigation was consistent with what happens in the field during a PI run.

The square infiltrometer analysis was carried out by calculating steady-state infiltration rates, $i_{s}\left(\mathrm{~L} \mathrm{~T}^{-1}\right)$, from the estimated steadystate flow rates, $Q_{S}$, and the infiltration surface, $A\left(\mathrm{~L}^{2}\right)$. The $i_{S}$ values for a given ring $\left(i_{s R}\right)$ were then compared with the corresponding $i_{s}$ data obtained by square infiltrometers equivalent to the ring infiltrometer in terms of wetted perimeter $\left(i_{S W P}\right)$, infiltration surface area $\left(i_{s I S}\right)$ and wetted perimeter per unit infiltration surface area $\left(i_{\text {SWPIS }}\right)$. For each dataset (Table 2), the linear regression line between two estimates of $i_{s}$ was determined and the confidence intervals for the intercept and the slope were calculated.

\section{Results and discussion}

The mass balance error did not exceed $0.6 \%$ for all simulations (Table 3). Therefore simulations were acceptable on the basis of existing evaluation criteria (Celia et al., 1990; Rathfelder and Abriola, 1994; Jacques et al., 2006).

According to the accuracy $K_{s}$ criterion, i.e. Eq. (7), the SR model yielded accurate predictions of $K_{S}$ for the sand (S), loamy sand (LS), sandy loam (SAL) and loam (L) soils (Table 3 ) and also, in practice, for the silt loam (SIL) soil since, for this soil, the error criterion was missed in a single case $\left(r=0.15 \mathrm{~m} ; d=0.03 \mathrm{~m} ; \Theta_{i}=0.05 ; H=0.05 \mathrm{~m}\right)$ and only by less than one percentage unity $\left(K_{S R E} / K_{s}=1.256\right)$. Generally, prediction of $K_{S}$ was not accurate for the SCL soil since the $K_{S R E} / K_{S}$ ratio fell outside the accuracy range in 10 out of the 16 considered cases. However, the predictions were accurate enough for this soil according to the less stringent accuracy criterion by Elrick and Reynolds (1992a).

The fact that the $K_{s}$ prediction accuracy was relatively poor for the SCL soil was probably due to an overestimation of steady-state flow rate since the duration of the infiltration runs was not long enough to approach steady-state conditions. To support this interpretation, it was initially considered that much longer infiltration times can be found in the literature for numerically simulated experiments. For example, Zhang et al. (1999) considered a simulation period of four days in an investigation on the concentric disk tension infiltrometer to improve detection of flow steadiness. This choice was not made in this investigation to maintain a correspondence in terms of duration between a simulated infiltration process and a field experiment, and considering that a two-hour simulation period generally allowed the detection of at least near steady-state conditions in the numerical study by Dušek et al. (2009). Equilibration times are known to increase with finer soil texture (Reynolds, 2008) and the inaccuracies were associated with the finest soil among the tested ones. In addition, time to steady-state is longer

\section{Table 3}

Summary of the i) mass balance errors (MBEs) for the simulated infiltration runs, and ii) ratios between the saturated soil hydraulic conductivity calculated with the model by Reynolds and Elrick (1990), $K_{S R E}$, and the theoretical saturated soil hydraulic conductivity, $K_{s}$, for the considered soils $\left(N=16\right.$ for a given soil; $4 \mathrm{r} / \mathrm{d}$ combinations $\times 2 \mathrm{H}$ levels $\times 2 \Theta_{i}$ values), and $r / \Theta_{i} / H$ combination yielding the lowest prediction error of $K_{s}$ for a ring insertion depth of $0.03 \mathrm{~m}$.

\begin{tabular}{|c|c|c|c|c|c|c|}
\hline \multirow[t]{2}{*}{ Soil } & \multicolumn{2}{|c|}{$\operatorname{MBE}(\%)$} & \multicolumn{2}{|c|}{$K_{S R E} / K_{S}$} & \multirow{2}{*}{$\begin{array}{l}r / \Theta_{i} / H \\
\text { combination }\end{array}$} & \multirow{2}{*}{$\begin{array}{l}\text { Absolute } \\
\text { percentage } \\
\text { error (\%) }\end{array}$} \\
\hline & Min & Max & Min & Max & & \\
\hline Sand, S & 0.012 & 0.24 & 0.97 & 1.14 & $0.038 / 0.05 / 0.05$ & 0.68 \\
\hline Loamy sand, LS & 0 & 0.052 & 0.96 & 1.12 & $0.038 / 0.05 / 0.05$ & 0.35 \\
\hline Sandy loam, SAL & 0.0005 & 0.27 & 0.89 & 1.18 & $0.038 / 0.05 / 0.10$ & 0.76 \\
\hline Loam, L & 0.007 & 0.56 & 0.95 & 1.10 & $0.038 / 0.05 / 0.10$ & 0.08 \\
\hline Silt loam, SIL & 0.011 & 0.60 & 0.86 & 1.26 & $0.038 / 0.4 / 0.10$ & 0.96 \\
\hline Silty clay loam, SCL & 0.028 & 0.32 & 1.05 & 2.02 & $0.038 / 0.4 / 0.10$ & 13.0 \\
\hline
\end{tabular}

$N=$ sample size; $r(\mathrm{~m})=$ ring radius; $d(\mathrm{~L})=$ ring insertion depth; $H(\mathrm{~m})=$ ponded depth of water; $\Theta_{i}=$ initial effective saturation, $\min =$ minimum, $\max =$ maximum. in drier soil conditions (Reynolds, 2008). With the first ponded depth of water, overestimation of $K_{s}$ for the SCL soil was more noticeable in initially dry conditions $\left(1.36 \leq K_{S R E} / K_{S} \leq 2.02\right.$, mean $\left.=1.58\right)$ than for initially wet conditions $\left(1.15 \leq K_{s R E} / K_{s} \leq 1.75\right.$, mean $\left.=1.36\right)$. To further test the $Q_{s}$ overestimation hypothesis, $K_{S R E}$ was also calculated for the SCL soil by using the steady-state flow rates determined by considering the last 10 min of a longer simulated infiltration process for a given $H$ (180 min instead of $120 \mathrm{~min}$ ). These calculations were carried out for all ring radii and both insertion depths for the smallest ring, yielding 16 estimates of $K_{s}$. The mean and the median of the $K_{s R E} / K_{s}$ ratios were equal to 1.38 and 1.36 , respectively, with the shorter runs and to 1.22 and 1.21 with the longer runs. This test, showing a closer agreement between $K_{S R E}$ and $K_{S}$ for the longer runs, also suggested that overestimation of $K_{s}$ was due to an overestimation of $Q_{s}$.

For $d=0.03 \mathrm{~m}$, the mean and the median of all $K_{S R E} / K_{s}$ values ( sample size $=24$ for a given radius) increased monotonically with $r$ from 1.03 to 1.21 and from 1.01 to 1.11 , respectively. According to this result, the performances of the SR model worsened as the ring radius increased but, on average, they remained satisfactory even with the largest source. A hypothesis needing testing is that prediction accuracy was lowest for $r=0.15 \mathrm{~m}$ because Eq. (2) was developed for ring radii not larger than $0.10 \mathrm{~m}$.

Therefore, applying the SR model by Reynolds and Elrick (1990) to a simulated PI experiment of reasonable duration generally allowed the obtainment of accurate predictions of $K_{s}$. These predictions can be less accurate in fine soils, probably because the risk to overestimate $Q_{s}$ is high in this case rather than for an inadequacy of the model. If only the order of magnitude of $K_{s}$ has to be determined, the SR model can also be applied in fine-textured and initially dry soils to analyze a relatively short experiment (i.e., not more than a few hours) carried out with rings of different radii $(0.038-0.15 \mathrm{~m})$ and ponding depths of water of $0.05-0.10 \mathrm{~m}$.

For an insertion depth of $0.03 \mathrm{~m}$, the developed dataset allowed the finding of the $r / \Theta_{i} / H$ combination yielding the smallest prediction error of $K_{S}$ for a given soil. This analysis was considered of practical interest because i) a ring insertion depth of $0.03 \mathrm{~m}$ should determine a minimal disturbance of the soil and ii) ring radius, ponded depth of water and, to a certain extent, soil water content at the time of the infiltration run can be controlled by the operator. As shown in Table 3, the lowest absolute percentage difference between the estimated and the true value of $K_{s}$ was obtained with the smallest ring $(r=0.038 \mathrm{~m})$ among the three tested sources for all soils, but the optimal values of $\Theta_{i}$ and $H$ (i.e., the values of these two parameters yielding the lowest percentage difference) differed with the soil. In particular, a dry soil should be sampled with a small ponded depth of water in the coarsest soils and with a high depth of water in intermediate soils. A fine-textured soil has to be relatively wet at the beginning of the run and a high depth of water has to be established on the infiltration surface. According to these results, adjustments in the relative importance of hydrostatic pressure, capillarity and gravity components of flow out of the ring are a tool to improve the accuracy of the $K_{s}$ estimates. Gravity flow contribution to total flow is known to increase with $r$ (Reynolds et al., 2002). Therefore, this contribution should be kept small to improve the quality of the $K_{s}$ prediction by using an infiltrometer of small radius. An increase of $H$ determines a more noticeable contribution of pressure flow and a reduced contribution of both capillary flow and gravity flow. Therefore, the contribution of pressure flow should increase in the passage from coarse- to fine-textured soils. Finally, wetter soil conditions generally determine less capillary flow, although the point at which increasing soil wetness starts to reduce soil capillarity depends on the shape of the $K(h)$ function. Therefore, capillary flow should be reduced in finetextured soils. A proper choice of the time of the run, determining the initial soil water content, the ring radius and the steady depth of ponding allows the obtainment of accurate predictions of $K_{s}$ (error $<25 \%$ ) even in fine-textured soils with a simulated infiltration run having a duration that can easily be established in the field. 

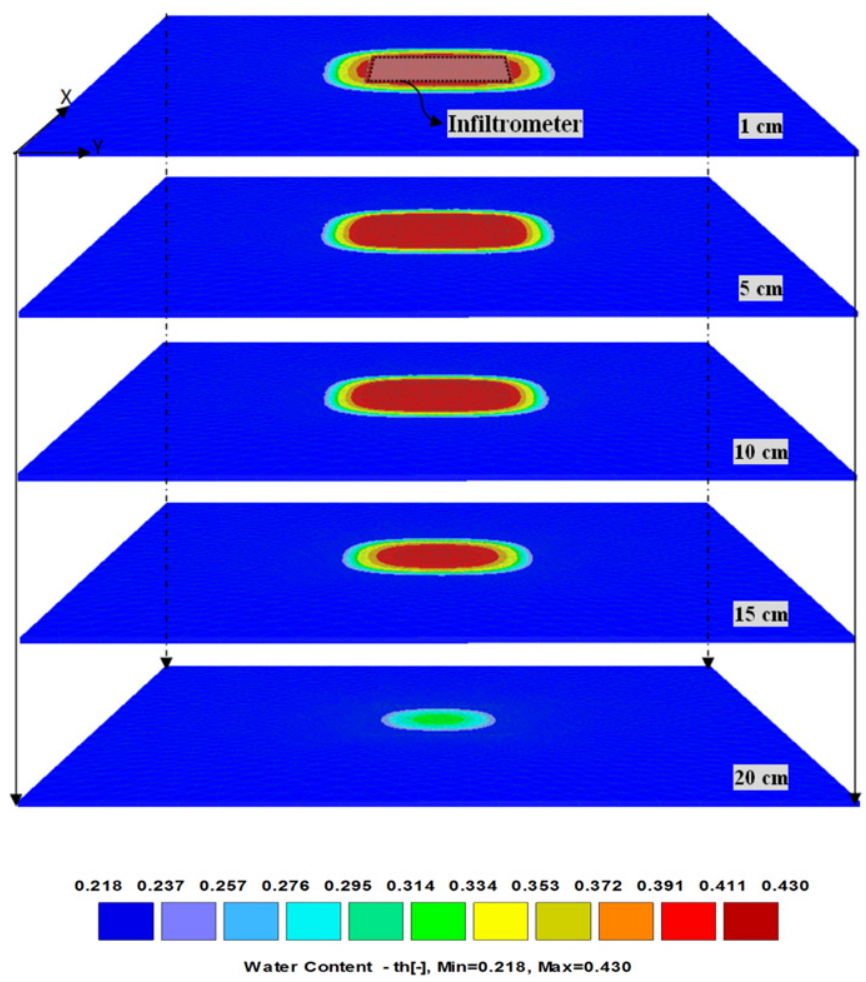

Fig. 3. Soil water distribution map at different depths for the square infiltrometer with side length $l=30 \mathrm{~cm}$ (loam soil, high initial water content) at infiltration time $t=120 \mathrm{~min}$.

The soil water distribution map for a ring infiltrometer was fairly different from that for a square infiltrometer in the initial stage of infiltration (Fig. 2). However, the differences gradually decreased as the infiltration proceeded and they became inappreciable for infiltration runs longer than $120 \mathrm{~min}$. Similarly, the wall influence of the square infiltrometer on the soil water distribution was noticeable in the top $5 \mathrm{~cm}$ of soil, but it hardly extended to a depth of more than $10 \mathrm{~cm}$ (Fig. 3).

The linear regression analysis between the steady-state infiltration rates estimated with a square and a single-ring pressure infiltrometer for different forms of equivalence between the two sources showed a statistically significant difference between $i_{s W P}$ and $i_{s R}$ for all $r$ and $d$ combinations (Table 4). Therefore, a square and a ring infiltrometer having the same wetted perimeter yielded different estimates of the steady-state infiltration rates. A statistically significant difference

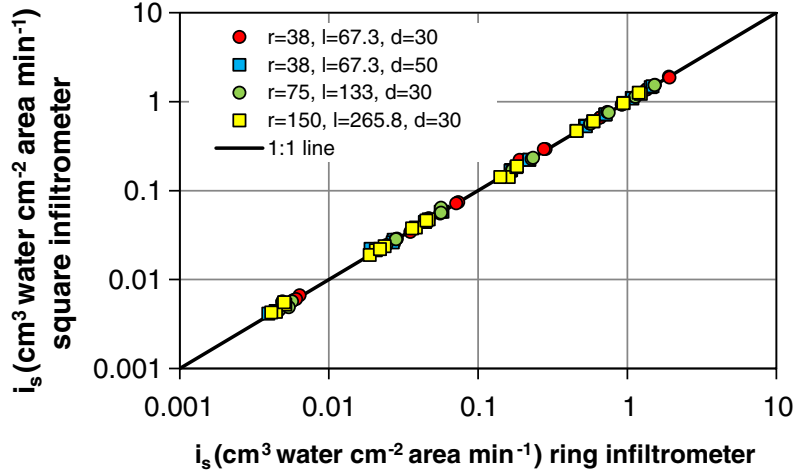

Fig. 4. Comparison between estimated steady-state infiltration rates with a ring and a square infiltrometer having the same infiltration area (IS scenario; $r=$ ring radius; $l=$ side length; $d=$ depth of insertion, all in $\mathrm{mm}$ ).

between corresponding estimates of $i_{s}$ was also detected when the equivalence was defined in terms of wetted perimeter per unit surface area, although only with reference to the dataset corresponding to a ring radius of $0.075 \mathrm{~m}$. Therefore, $i_{\text {SWPIS }}$ did not coincide with $i_{S R}$ for all datasets and the conclusion was that a square and a ring infiltrometer having the same wetted perimeter per unit surface area did not yield in general similar estimates of the steady-state infiltration rates. For all datasets, a statistical coincidence between $i_{S I S}$ and $i_{S R}$ was recognized (Fig. 4) according to the 95\% (three datasets) or the 99\% (all datasets) confidence intervals for the intercept and the slope (Table 4). Therefore, this analysis suggested that the shape of the infiltration surface did not influence significantly steady infiltration rates. An implication of this result is that saturated soil hydraulic conductivity can be determined by using the steady-state infiltration data collected by a square infiltrometer and the relationships by Reynolds and Elrick (1990), because it is possible to assume that infiltration occurs through a circular area having the same size of the area sampled by the square infiltrometer. In other terms, the equivalent radius, $r_{e q}(\mathrm{~L})$, that replaces $r$ in the SR model when steady-state flow rates are obtained from a square source is:

$r_{e q}=\frac{l}{\sqrt{\pi}}$

where $l(\mathrm{~L})$ is the side length of the square infiltrometer. With this assumption, the values of $K_{s}$ calculated with $i_{s I S}$, Eqs. (2) and (3) and the true value of $\alpha^{*}$ differed from the corresponding values obtained with $i_{\text {sR }}$ by not more than $15.8 \%$ (mean and median of the absolute percentage

Table 4

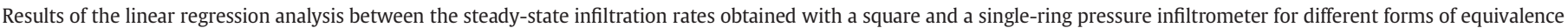
between the two sources.

\begin{tabular}{|c|c|c|c|c|c|c|c|c|c|c|}
\hline \multirow[t]{2}{*}{$r(\mathrm{~m})$} & \multirow[t]{2}{*}{$d(\mathrm{~m})$} & \multirow[t]{2}{*}{$L(\mathrm{~m})$} & \multirow[t]{2}{*}{ Equivalence by } & \multirow[t]{2}{*}{$b_{0}$} & \multirow[t]{2}{*}{$b_{1}$} & \multirow[t]{2}{*}{$R^{2}$} & \multicolumn{2}{|c|}{ 95\% confidence intervals } & \multicolumn{2}{|c|}{ 99\% confidence intervals } \\
\hline & & & & & & & $b_{0}$ & $b_{1}$ & $b_{0}$ & $b_{1}$ \\
\hline \multirow{3}{*}{0.038} & 0.03 & 0.0596 & WP & -0.0005 & 1.0356 & 0.9998 & $-0.0057-+0.0046$ & $1.029-1.042$ & $-0.0075-+0.0065$ & $1.026-1.045$ \\
\hline & & 0.0673 & IS & +0.0060 & 0.9926 & 0.9994 & $-0.0020-+0.0139$ & $0.982-1.003$ & $-0.0048-+0.0166$ & $0.978-1.007$ \\
\hline & & 0.0760 & WPIS & -0.0005 & 0.9763 & 0.9980 & $-0.0150-+0.0140$ & $0.957-0.995$ & $-0.0202-+0.0192$ & 0.950-1.002 \\
\hline \multirow{3}{*}{0.038} & 0.05 & 0.0596 & WP & -0.0047 & 1.058 & 0.9990 & $-0.0135-+0.0042$ & $1.043-1.073$ & $-0.0167-+0.0074$ & $1.038-1.078$ \\
\hline & & 0.0673 & IS & +0.0006 & 1.0031 & 0.9999 & $-0.0018-+0.0030$ & $0.999-1.007$ & $-0.0026-+0.0039$ & 0.998-1.009 \\
\hline & & 0.0760 & WPIS & +0.0009 & 0.9906 & 0.9981 & $-0.0105-+0.0122$ & $0.971-1.010$ & $-0.0146-+0.0163$ & 0.964-1.017 \\
\hline \multirow{3}{*}{0.075} & 0.03 & 0.1178 & WP & -0.0029 & 1.0350 & 0.9990 & $-0.0118-+0.0061$ & $1.020-1.049$ & $-0.0150-+0.0093$ & $1.015-1.055$ \\
\hline & & 0.1330 & IS & +0.0010 & 1.0010 & 0.9999 & $-0.0019-+0.0040$ & $0.996-1.006$ & $-0.0030-+0.0051$ & 0.994-1.008 \\
\hline & & 0.1500 & WPIS & -0.0005 & 0.9687 & 0.9998 & $-0.0040-+0.0030$ & $0.963-0.974$ & $-0.0052-+0.0043$ & $0.961-0.976$ \\
\hline \multirow{3}{*}{0.150} & 0.03 & 0.2356 & WP & -0.0008 & 1.0521 & 0.9996 & $-0.0053-+0.0037$ & $1.043-1.061$ & $-0.0069-+0.0053$ & $1.040-1.064$ \\
\hline & & 0.2659 & IS & -0.0017 & 1.0187 & 0.9991 & $-0.0086-+0.0052$ & $1.005-1.032$ & $-0.0110-+0.0077$ & $1.000-1.037$ \\
\hline & & 0.3000 & WPIS & +0.0005 & 0.9674 & 0.9959 & $-0.0132-+0.0141$ & $0.940-0.995$ & $-0.0181-+0.0191$ & $0.930-1.005$ \\
\hline
\end{tabular}

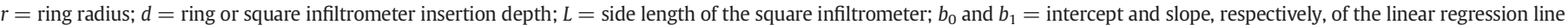

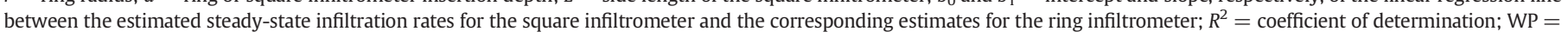
wetted perimeter; IS = infiltration surface area; WPIS = wetted perimeter per unit area of the infiltration surface. 


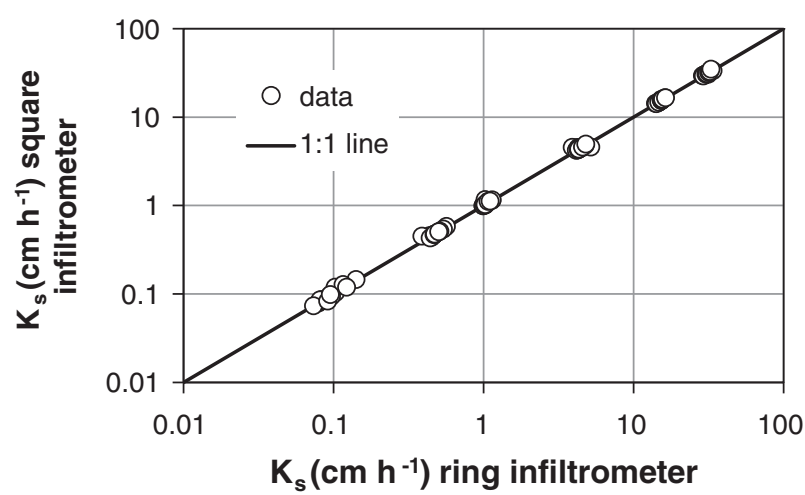

Fig. 5. Comparison between the saturated soil hydraulic conductivity, $K_{s}$, estimates obtained by the ring and the square infiltrometer.

differences $=2.2 \%$ and $0.8 \%$, respectively, Fig. 5), confirming the strong similarity between the estimates of $K_{s}$ obtained by a ring and a square infiltrometer sampling an infiltration surface of the same size.

\section{Conclusions}

For sand to silt loam soils, the steady-state analysis developed by Reynolds and Elrick (1990) for a single-ring pressure infiltrometer (PI) is expected to yield accurate estimates of saturated soil hydraulic conductivity, $K_{s}$ (i.e., error $\leq 25 \%$ ), when it is applied to a numerically simulated infiltration experiment with durations (2-4 h), ring radii $(0.038 \leq r \leq 0.15 \mathrm{~m})$, ponding depths of water $(H=0.05-0.10 \mathrm{~m})$ and initial saturation degrees $\left(\Theta_{i}=0.05-0.4\right)$ that are common for a field application of the PI.

In the fine-textured silty clay loam soil, $K_{s}$ was generally overestimated. This overestimation was not substantial according to some accuracy criteria (i.e., it did not exceed a factor of nearly two) and it occurred because the experiment was too short to approach steady-state conditions. In this case too, however, an accurate estimate of $K_{s}$ can be obtained with a proper experimental methodology for the considered duration of the experiment, i.e. by maximizing the hydrostatic pressure component of flow compared with the gravity and capillarity components. In practice, a small ring and relatively high initial soil water content and $H$ level are recommended.

The analysis by Reynolds and Elrick (1990) is also usable to analyze steady-state infiltration data collected with a square infiltrometer. In this case, however, an equivalent radius has to be used in the calculations.

In this investigation, homogeneous soil conditions were considered but numerical simulation can also be performed taking into account $K_{s}$ heterogeneity. Therefore, the effect of soil heterogeneity on both the steady-state analysis of a single-ring infiltration process and the infiltrometer data obtained with sources of different geometric shape will be tested in the future, taking into account that heterogeneity is a common occurrence in the field.

\section{Acknowledgments}

All authors contributed in the outline of the investigation, analysis of the data, discussion of the results, and the writing the manuscript. J. Lai performed numerical simulation of the infiltration runs.

\section{References}

Angulo-Jaramillo, R., Vandervaere, J.-P., Roulier, S., Thony, J.L., Gaudet, J.P., Vauclin, M., 2000. Field measurement of soil surface hydraulic properties by disc and ring infiltrometers. A review and recent developments. Soil Tillage Res. 55, 1-29.

Bagarello, V., Iovino, M., 1999. Spatial and temporal variability of saturated hydraulic conductivity in a central Sicily soil. Proceedings of the International Workshop of
EurAgEng's Field of Interest on Soil and Water "Modelling of Transport Processes in Soils", Leuven, Belgium, pp. 249-256.

Bagarello, V., Sgroi, A., 2004. Using the single-ring infiltrometer method to detect temporal changes in surface soil field-saturated hydraulic conductivity. Soil Tillage Res. 76, 13-24.

Bagarello, V., Iovino, M., Tusa, G., 2000. Factors affecting measurement of the near saturated soil hydraulic conductivity. Soil Sci. Soc. Am. J. 64, 1203-1210.

Bagarello, V., Iovino, M., Lai, J., 2013a. Field and numerical tests of the two-ponding depth procedure for analysis of single-ring pressure infiltrometer data. Pedosphere 23, 779-789.

Bagarello, V., Di Stefano, C., Iovino, M., Sgroi, A., 2013b. Using a transient infiltrometric technique for intensively sampling field-saturated hydraulic conductivity of a clay soil in two runoff plots. Hydrol. Process. 27, 3415-3423. http://dx.doi.org/10.1002/ hyp.9448.

Bagarello, V., Baiamonte, G., Castellini, M., Di Prima, S., Iovino, M., 2014. A comparison between the single ring pressure infiltrometer and simplified falling head techniques. Hydrol. Process. 28, 4843-4853. http://dx.doi.org/10.1002/hyp.9980.

Bouma, J., 1982. Measuring the hydraulic conductivity of soil horizons with continuous macropores. Soil Sci. Soc. Am. J. 46, 438-441.

Carsel, R.F., Parrish, R.S., 1988. Developing joint probability distributions of soil water retention characteristics. Water Resour. Res. 24, 755-769.

Celia, M.A., Boulouton, E.T., Zarba, R.L., 1990. A general mass conservation numerical solution for the unsaturated flow equation. Water Resour. Res. 26 (7), 1483-1496.

Ciollaro, G., Lamaddalena, N., 1998. Effect of tillage on the hydraulic properties of a vertic soil. J. Agric. Eng. Res. 71, 147-155.

Dušek, J., Dohnal, M., Vogel, T., 2009. Numerical analysis of ponded infiltration experiment under different experimental conditions. Soil Water Res. 4, S22-S27.

Elrick, D.E., Reynolds, W.D., 1992a. Methods for analyzing constant-head well permeameter data. Soil Sci. Soc. Am. J. 56, 320-323.

Elrick, D.E., Reynolds, W.D., 1992b. Infiltration from constant-head well permeameters and infiltrometers. In: Topp, G.C., Reynolds, W.D., Green, R.E. (Eds.), Advances in Measurement of Soil Physical Properties: Bringing Theory Into Practice, SSSA Special Publication No. 30, Madison, WI, USA, pp. 1-24.

Elrick, D.E., Reynolds, W.D., Geering, H.R., Tan, K.A., 1990. Estimating steady infiltration rate times for infiltrometers and permeameters. Water Resour. Res. 26 (4), 759-769.

Gómez, J.A., Vanderlinden, K., Nearing, M.A., 2005. Spatial variability of surface roughness and hydraulic conductivity after disk tillage: implications for runoff variability. J. Hydrol. 311, 143-156.

Haverkamp, R., Vauclin, M., Touma, J., Wierenga, P.J., Vachaud, G., 1977. A comparison of numerical simulations models for one-dimensional infiltration. Soil Sci. Soc. Am. J. 41, 285-294.

Hinnell, A.C., Lazarovitch, N., Warrick, A.W., 2009. Explicit infiltration function for boreholes under constant head conditions. Water Resour. Res. 45 (W10429, 9 pages).

Jacques, D., Šimůnek, J., Mallants, D., van Genuchten, M.Th., 2006. Operator-splitting errors in coupled reactive transport codes for transient variably saturated flow and contaminant transport in layered soil profiles. J. Contam. Hydrol. 88, 197-218.

Lai, J., Ren, L., 2007. Assessing the size dependency of measured hydraulic conductivity using double-ring infiltrometers and numerical simulation. Soil Sci. Soc. Am. J. 71, 1667-1675.

Lai, J., Luo, Y., Ren, L., 2010. Buffer index effects on hydraulic conductivity measurements using numerical simulations of double-ring infiltration. Soil Sci. Soc. Am. J. 74, 1526-1536.

Mertens, J., Jacques, D., Vanderborght, J., Feyen, J., 2002. Characterisation of the fieldsaturated hydraulic conductivity on a hillslope: in situ single ring pressure infiltrometer measurements. J. Hydrol. 263, 217-229.

Mualem, Y., 1976. A new model for predicting the hydraulic conductivity of unsaturated porous media. Water Resour. Res. 12, 513-522.

Rathfelder, K., Abriola, L.M., 1994. Mass conservative numerical solutions of the headbased Richards equation. Water Resour. Res. 30 (9), 2579-2586.

Reynolds, W.D., 2008. Chapter 77. Saturated hydraulic properties: ring infiltrometer. In: Carter, M.R., Gregorich, E.G. (Eds.), Soil Sampling and Methods of Analysis, Second edition CRC Press, Taylor \& Francis Group, Boca Raton, FL, USA, Canadian Society of Soil Science, pp. 1043-1056.

Reynolds, W.D., 2010. Measuring soil hydraulic properties using a cased borehole permeameter: steady flow analyses. Vadose Zone J. 9, 637-652.

Reynolds, W.D., 2011. Measuring soil hydraulic properties using a cased borehole permeameter: falling-head analysis. Vadose Zone J. 10, 999-1015.

Reynolds, W.D., 2013. An assessment of borehole infiltration analyses for measuring fieldsaturated hydraulic conductivity in the vadose zone. Eng. Geol. 159, 119-130.

Reynolds, W.D., Elrick, D.E., 1990. Ponded infiltration from a single ring: I. Analysis of steady flow. Soil Sci. Soc. Am. J. 54, 1233-1241.

Reynolds, W.D., Elrick, D.E., 2002. 3.4.3.2.b Pressure infiltrometer. In: Dane, J.H., Topp, G.C. (Eds.), Methods of Soil Analysis, Part 4, Physical Methods, Number 5 in the Soil Science Society of America Book Series. Soil Science Society of America, Inc., Madison, WI, USA, pp. 826-836.

Reynolds, W.D., Lewis, J.K., 2012. A drive point application of the Guelph permeameter method for coarse-textured soils. Geoderma 187, 59-66. http://dx.doi.org/10.1016/ j.geoderma.2012.04.004.

Reynolds, W.D., Bowman, B.T., Brunke, R.R., Drury, C.F., Tan, C.S., 2000. Comparison of tension infiltrometer, pressure infiltrometer, and soil core estimates of saturated hydraulic conductivity. Soil Sci. Soc. Am. J. 64, 478-484.

Reynolds, W.D., Elrick, D.E., Youngs, E.G., 2002. 3.4.3.2.a Single-ring and double- or concentric-ring infiltrometers. In: Dane, J.H., Topp, G.C. (Eds.), Methods of Soil Analysis, Part 4, Physical Methods, Number 5 in the Soil Science Society of America Book Series. Soil Science Society of America, Inc., Madison, WI, USA, pp. 821-826. 
Shan, Y., Wang, Q., 2012. Simulation of salinity distribution in the overlap zone with double-point-source drip irrigation using HYDRUS-3D. Aust. J. Crop. Sci. 6 (2), 238-247.

Šimůnek, J., Šejan, M., van Genuchten, M.T., 2007. The HYDRUS software package for simulating two-and three-dimensional movement of water, heat, and multiple solutes in variably-saturated media. Technical Manual, Version 1.0. PC Progress, Prague, Czech Republic.

van Genuchten, M.T., 1980. A closed-form equation for predicting the hydraulic conductivity of unsaturated soils. Soil Sci. Soc. Am. J. 44 (5), 892-898.

Vauclin, M., Elrick, D.E., Thony, J.L., Vachaud, G., Revol, Ph., Ruelle, P., 1994. Hydraulic conductivity measurements of the spatial variability of a loamy soil. Soil Technol. 7, 181-195.

Verbist, K., Baetens, J., Cornelis, W.M., Gabriels, D., Torres, C., Soto, G., 2009. Hydraulic conductivity as influenced by stoniness in degraded drylands of Chile. Soil Sci. Soc. Am. J. $73,471-484$.
Verbist, K., Torfs, S., Cornelis, W.M. Oyarzún, R., Soto, G Gabriels, D, 2010 Comparison of single- and double-ring infiltrometer methods on stony soils. Vadose Zone J. 8, 462-475.

Verbist, K.M.J., Cornelis, W.M., Torfs, S., Gabriels, D., 2013. Comparing methods to determine hydraulic conductivities on stony soils. Soil Sci. Soc. Am. J. 77, 25-42.

Wu, L., Swan, J.B., Nieber, J.L., Allmaras, R.R., 1993. Soil-macropore and layer influences on saturated hydraulic conductivity measured with borehole permeameters. Soil Sci. Soc. Am. J. 57, 917-923.

Wu, L., Pan, L., Mitchell, J., Sanden, B., 1999. Measuring saturated hydraulic conductivity using a generalized solution for single-ring infiltrometers. Soil Sci. Soc. Am. J. 63, 788-792.

Youngs, E.G., Elrick, D.E., Reynolds, W.D., 1993. Comparison of steady flows from infiltration rings in "Green and Ampt" and "Gardner" soils. Water Resour. Res. 29, 1647-1650.

Zhang, Y., Smith, R.E., Butters, G.L., Cardon, G.E., 1999. Analysis and testing of a concentricdisk tension infiltrometer. Soil Sci. Soc. Am. J. 63, 544-553. 